\title{
Similar Physical Simulation on the Deformation of Surrounding Rocks of Floor Roadway Caused by Coal Mining Under Tectonic Stress
}

\author{
Zhongsi Dou ${ }^{1,2, *}$, Jiwen $\mathrm{Wu}^{1}$, Liang Wang ${ }^{3}$, Xiaorong Zhai ${ }^{1}$, Wenquan $\mathrm{Li}^{2}$, luo $\mathrm{Lu}^{2}$ and Yangzhou $\mathrm{Ma}^{4}$ \\ ${ }^{1}$ School of Earth and Environment, Anhui University of Science \& Technology, Huainan 232001, China \\ ${ }^{2}$ Huainan Vocational Technical College, Huainan 232001, China \\ ${ }^{3}$ SINOSTEEL Maanshan Institute of Mining Research Co, Ltd, Maanshan 243003, China \\ ${ }^{4}$ ICB UMR 6303 CNRS, Univ. Bourgogne Franche-Comté,UTBM,F-90010,Belfort, France
}

Received 14 December 2016; Accepted 16 April 2017

\begin{abstract}
At present, the instability of floor roadway is increasingly serious, and even the representative high-performance U-steel support cannot provide roadways with completely effective support. Thus, the mechanism of roadway deformation should be analyzed rather than only considering the roadway support. To study the influence of coal mining on the stability of floor roadways under tectonic stress, taking the floor roadway under No.8 coal seam in Luling Coal Mine in China as the research object, the roadway deformation was tested with and without tectonic stress through the similar physical simulation method. Finally, the changing mechanisms of the stress field, fracture development and displacement field of the surrounding rocks in the floor roadway under mining effects were systematically analyzed. The results show that: (1) under the same stress condition, deformation and fracture of the floor roadway increase with the increase of mining step; (2) without tectonic stress, the maximum hoop stress of the floor roadway arch foot is $32.5 \mathrm{MPa}$ located 2.7 $\mathrm{m}$ away from the roadway wall. Meanwhile, under tectonic stress, the maximum stress changes to $38.5 \mathrm{MPa}$ at $3.6 \mathrm{~m}$ away from the roadway wall; (3) whether under mining effects or not, the deformation time is longer and deformation failure is larger under tectonic stress. The conclusions indicate the tectonic stress field has significant on roadway deformation and failure, which can provide the technical reference for the optimization of mine roadway layout.
\end{abstract}

Keywords: Tectonic stress, Floor roadway, Similar physical simulation, Surrounding rocks

\section{Introduction}

Crustal stress is the power source of all mining accidents [1]. Despite people having known the existence of crustal stress for nearly a century, they still fail to master the essence of the problems and rules regarding the spatial stress field induced by underground mining. Moreover, the design of underground mining projects is usually lacking of adequate scientific bases, and numerous control and support methods of rock strata are lacking of effective means, which ultimately results in underground disasters, such as rib fall of coal walls, roadway roof fall, deformation and damage of support, coal-gas outburst, and casualty among workers [2-4]. The deformation and failure of the surrounding rocks of roadways are mainly the result of the strength of surrounding rocks and stress application, the strength of surrounding rocks depends on the lithological characteristics of the rocks, and the stress depends on roadway depth and geological tectonism. From rock to coal roadways, and static to dynamic roadways, researches on these types gradually focuses on various complicated roadways. Studies on crustal stress focus not merely on gravity stress but also on the mutual effect of gravity, tectonic, and supporting stresses [5-7].

Whether from theory itself or national economy and application of project practice, the disturbance and rule change in the spatial stress field and the deformation failure

\footnotetext{
*E-mail address: hnzyjsxydzs@163.com
}

ISSN: 1791-2377 @ 2017 Eastern Macedonia and Thrace Institute of Technology. All rights reserved. characteristics of roadways combined with the characteristics of underground mining engineering should be studied.

Existing studies primarily focused on evaluating the stability of surrounding rocks of roadways, calculating stress, and simulating experiments [8-10]. However, with the increase in mining depth and complexity of crustal stress environments, the present stability analyzing of floor roadway on specific environments is insufficient to demonstrate that roadway stability results from tectonic stress. Thus, a comparative study is necessary to reveal the influence of tectonic stress on roadway deformation [11-13]. Moreover, coal mines in China are mostly multi-seam coal mines, and the problem of mining stress is inevitable and ubiquitous; thus, conducting research on the rules of transfer of mining stress and floor roadway deformation is necessary.

On the basis of the above mentioned conditions, the influence of coal mining on the floor roadway under tectonic stress is studied through a similar physical simulation. This study can reveal the failure mechanism of floor roadway under different stress conditions and the role of tectonic stress on the failure of floor roadway. Moreover, the study can provide a theoretical basis for roadway layout and support.

\section{State of the art}

Numerous researchers have studied the mechanism of deformation failure of surrounding rocks. The methods adopted have changed from elastic and elastic-plastic theory to rheology. 
At present, elastic-plastic and rheological analyses still dominate the research methodology, whereas damage, breakage, and dilatation are gradually becoming research interests [14-18]. Numerical simulation [19-21] and indoor simulation experiments [22] are relatively direct research methods.

He et al. conducted a numerical simulation on a roadway in Xing dong Mine using FLAC3D; they also performed spot tests and underground trials and concluded the instability mechanism of high-ground stress roadway under the mining stress was brought by excavation, which caused the shear dislocation of the rock stratum and further resulted in the dilatation and large deformation of surrounding rocks [23]. Guo et al. utilized a numerical simulation software to introduce the reasons for the deformation and damage of soft rock roadways under tectonic stress; the frequently occurring stress of surrounding rocks of roadways caused by complicated tectonic stress and low rock mass strength made the previous support barely adapt to the large deformation of deep roadways [24]. Zheng studied the optimal direction of floor roadway with field measurement and theoretical analysis, and analyzed the relationship between optimal direction of roadway layout and the maximum principal stress direction. The results showed the optimal direction of roadway layout was not parallel to the direction of maximum principal stress but instead with a certain angle, and the angle depended on the ratio of three principal stress [25]. The analytical expressions of the abovementioned studies are merely concluded from numerical simulations. However, analysis of surrounding rocks of floor roadway is a complicated geotechnical problem. Therefore, accuracy in numerical analysis is necessary. Field measurement is one of the most accurate methods; however, it is difficult to realize whether in economy or technique. One of the most potent ways in studying underground space is the similar physical simulation.

Xiao et al. studied the stability of surrounding rocks of deep coal mine under tectonic stress using a similar physical simulation; they concluded that horizontal stress on the roadway top presented a distribution pattern which was "low on both sides and high in the middle". The destruction degree of the roadway top was proportional to the stress, and the peak stress shifted to the depth of the top coal with the increase of tectonic stress [26]. Li et al. considered that the drivage destroyed the original stress field and redistributed the stress of the surrounding rocks; and that the high concentration of stress in an area caused the deformation and destruction of the surrounding rocks of roadways [27]. Jiang et al. regarded that surrounding rocks commonly ruptured and formed different partitions during destruction, in which the surrounding rocks became enlarged under confining stress[28]. The abovementioned studies have analyzed the effect of tectonic stress on roadway stability from different perspectives; however, no contrast experiments with and without tectonic stress were conducted.

Based on existing studies, domestic and foreign scholars have focused on floor roadways under tectonic stress; however, certain deficiencies still exist. First, most analytical expressions are obtained by numerical simulation rather than similar material simulation. Second, in terms of modeling, the similar model is established only under one stress condition, whereas a comparison under another stress condition is not considered. Moreover, the deformation of the mining floor roadway caused by tectonic stress is difficult to determine accurately.

Given the above situations, the present study designs a similar simulation program combined with the mastery of field measurement data to analyze the influence of upper coal face mining on the stability of surrounding rocks of floor roadways with and without tectonic stress. Then, stress in the surrounding rocks of roadways and rules of fracture development are analyzed.

The remainder of this study is organized as follows. Section 3 establishes a similar material model, which has received efficient and reliable data based on the roadway layout and the Rock Mechanics Testing Systems (MTS) uniaxial compression tests of Lu ling Mine to make the parameters and spatial relationships comply with actual circumstances. Section 4 analyzes roadway deformation under different mining steps, with and without tectonic stress. Finally, Section 5 summarizes and concludes the study.

\section{Methodology}

3.1 Experimental data sources and processing methods 3.1.1Engineering technology background of the coal mine According to the exploration data of the Luling Coal Mine, the thickness of No.8 coal seam is $10.58 \mathrm{~m}$, and the elevation level is $-590 \mathrm{~m}$. Figure 1 shows a normal fault near the seam, which leads to rock failure.

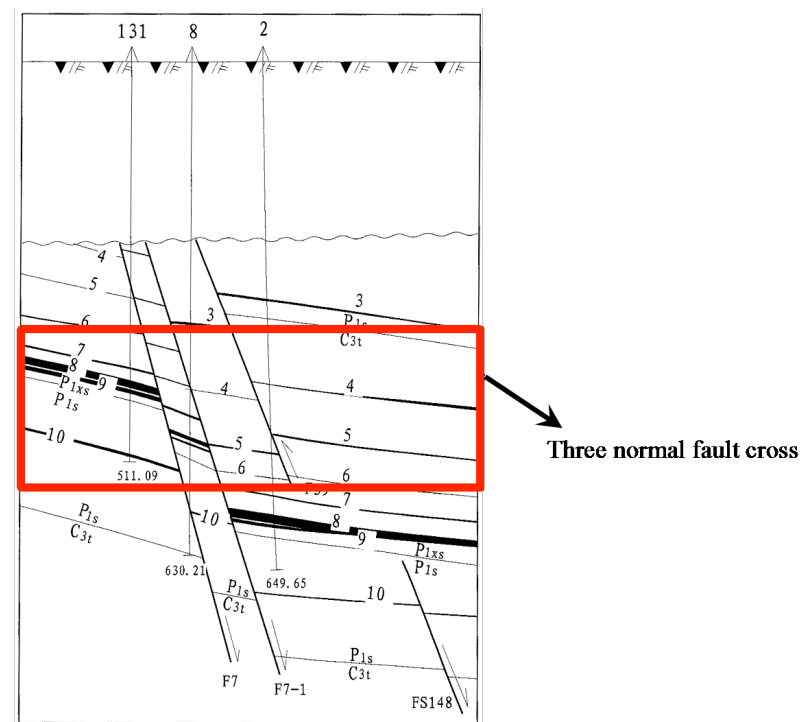

Fig. 1. Borehole histogram around the coal mine

The vertical distance from the floor roadway to the coal seam is $35 \mathrm{~m}$, and the floor roadway consists of soft stone, whereas the surrounding rock mainly consists of siltstone and mudstone. The height of the vertical wall is $2 \mathrm{~m}$, and the radius of the upper round arch is $3 \mathrm{~m}$. The mining of coal seam is later than the floor roadway drivage. Figure 2 shows the borehole histogram of the mine.

Table 1 shows the mechanical parameters of the rocks obtained by MTS uniaxial compression tests.

Table 1. Strength of rock samples

\begin{tabular}{l|l|l|l|l}
\hline Lithology & $\begin{array}{l}\text { Elastic } \\
\text { modulus/ } \\
\text { GPa }\end{array}$ & $\begin{array}{l}\text { Tensile } \\
\text { strength/ } \\
\text { GPa }\end{array}$ & $\begin{array}{l}\text { Compre } \\
\text { ssive } \\
\text { strength/ } \\
\text { MPa }\end{array}$ & $\begin{array}{l}\text { Shear } \\
\text { strength/ } \\
\text { MPa }\end{array}$ \\
\hline Siltstone & 8.06 & 3.15 & 18.15 & 7.56 \\
Mudstone & 6.19 & 2.43 & 12.36 & 3.84 \\
Raw coal & 3.56 & 1.12 & 5.78 & 1.47 \\
\hline
\end{tabular}

\subsubsection{Methods for roadway simulation data processing}

Using polar coordinates is an easy method to express strain in roadways. The maximum, median, and minimum values of stress (indicated as $\sigma_{1}, \sigma_{2}$, and $\sigma_{3}$ ) were expressed as hoop, axial, and radial stresses (indicated as $\sigma_{\theta}, \sigma_{z}$, and $\sigma_{r}$ ), respectively. 


\begin{tabular}{|c|c|c|c|c|c|c|c|c|}
\hline $\begin{array}{l}\text { Rock } \\
\text { Layer }\end{array}$ & Lithology & Histgram & Thickness/m & Depth $/ \mathrm{m}$ & \multirow{11}{*}{ 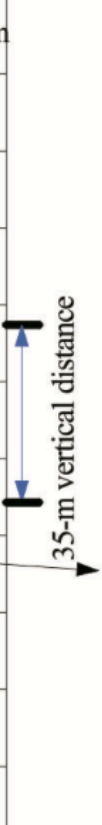 } & \multirow{11}{*}{$6000 \mathrm{~mm}$} & \multirow{11}{*}{ 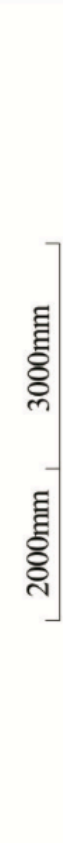 } & \\
\hline 1 & Siltstone & 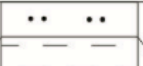 & 6.25 & -544.7 & & & & \\
\hline 2 & Mudstone & --- & 19.26 & -551.0 & & & & \\
\hline 3 & Siltstone & $\cdots$ & 6.53 & -570.2 & & & & 苛 \\
\hline 4 & Mudstone & 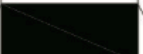 & 13.25 & -576.8 & & & & I \\
\hline 5 & Coal & --- & 10.58 & -590.0 & & & & + \\
\hline 6 & Mudstone & $\cdots$ & 18.78 & -600.6 & & & & 尝 \\
\hline 7 & Siltstone & ---1 & 7.06 & -619.4 & & & & $=$ \\
\hline 8 & Mudstone & $\cdots \cdots$ & 18.15 & -626.4 & & & & 莺 \\
\hline 9 & Siltstone & ---1 & 8.20 & -644.9 & & & & \\
\hline 10 & Mudstone & --- & 30.86 & -653.1 & & & & \\
\hline
\end{tabular}

Fig. 2. Borehole histogram of the mine

In situ rock samples are shown in Figure 3, in which 1, 2, and 3 represent siltstone, mudstone, and raw coal, respectively.

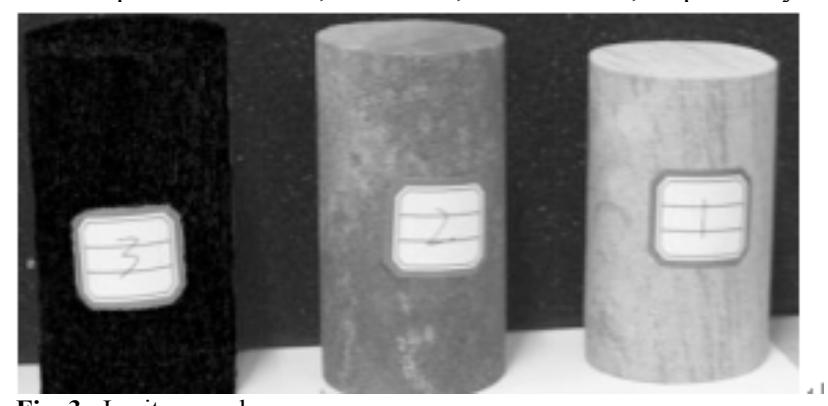

Fig. 3. In situ samples

In the 3D stress field, according to the generalized Hooke's law:

$$
\frac{(1+v)\left(\sigma_{\theta}-\sigma_{\mathrm{r}}\right)}{\mathrm{E}}=\varepsilon_{\theta}-\varepsilon_{\mathrm{r}}
$$

On the basis of differential equations of equilibrium:

$$
\frac{\mathrm{d} \sigma_{\mathrm{r}}}{\mathrm{dr}}-\frac{\sigma_{\mathrm{r}}-\sigma_{\mathrm{r}}}{\mathrm{r}}=0
$$

The corresponding hoop and radial stresses are :

$$
\left\{\begin{array}{l}
\sigma_{\theta}=\frac{E}{1+v}\left(\varepsilon_{\theta}-\varepsilon_{r}\right)+\sigma_{r} \\
\sigma_{r}=r^{\frac{E}{1+v}\left(\varepsilon_{\theta}-\varepsilon_{r}\right)} e^{-3.27}
\end{array}\right.
$$

Floor roadway stability in the mining process was analyzed based on the distribution of stress from the surrounding rocks and strain field.
3.2 Similar Physical Simulation

3.2.1 Analog proportion design and experiment table assembly

The simulation experiment was based on the three theorems of analogy. The ratio of similitude in the simulation was determined as follows.

1) Geometry ratio of similitude: The height of the roadway vertical wall was $2 \mathrm{~m}$, and the radius was $3 \mathrm{~m}$. To avoid size effect, the length $\times$ height $\times$ thickness of the boundary was 90 $\mathrm{m} \times 60 \mathrm{~m} \times 15 \mathrm{~m}$, and the size of the model was $1.8 \mathrm{~m} \times 1.2$ $\mathrm{m} \times 0.3 \mathrm{~m}$. The vertical wall of the simulation roadway was 4 $\mathrm{cm}$ with a radius of $6 \mathrm{~cm}$. The geometry ratio is $C_{L}=1: 45$.

2) Appearance density ratio of similitude: The test on the physical and mechanical parameters of the prototype and standard specimen model indicated that the volume weight ratio of similitude is $C_{\gamma}=1: 1.2$.

3) Stress ratio of similitude: $C_{\sigma}=C_{L} \times C_{\gamma}=1: 54$.

4) Relation between loading of jack and boundary loads: Horizontal loading: the lateral area was $120 \mathrm{~cm} \times 30 \mathrm{~cm}=3600$ $\mathrm{cm}^{2}$. Each lateral area had two pistons. The entire area was 56 $\mathrm{cm}^{2}$. Thus, the ratio of lateral oil pressure and lateral boundary loads was 64.286:1; Vertical loading: The roof area was $180 \mathrm{~cm}$ $\times 30 \mathrm{~cm}=5400 \mathrm{~cm}^{2}$. Two pistons were in the roof. The entire area was $56 \mathrm{~cm}^{2}$. Thus, the ratio of roof oil pressure and boundary loads was $96.43: 1$.

A plane stress loading experiment device was assembled by a jack, and a similar simulation experiment frame, which was combined with plane model shelf, jack, flange plate, and highduty bolt, was conducted. The jack and flange were set at the top and the left and right sides of the model shelf by a high-duty bolt, which formed a plane counter-force experiment device. The size of the experiment table was $3 \mathrm{~m} \times 2 \mathrm{~m} \times 0.3 \mathrm{~m}$, and the size of model was $1.8 \mathrm{~m} \times 1.2 \mathrm{~m} \times 0.3 \mathrm{~m}$. The vertical wall of the simulation roadway was $2 \mathrm{~cm}$ with a radius of $3 \mathrm{~cm}$. Figure 4 shows the device setup. 


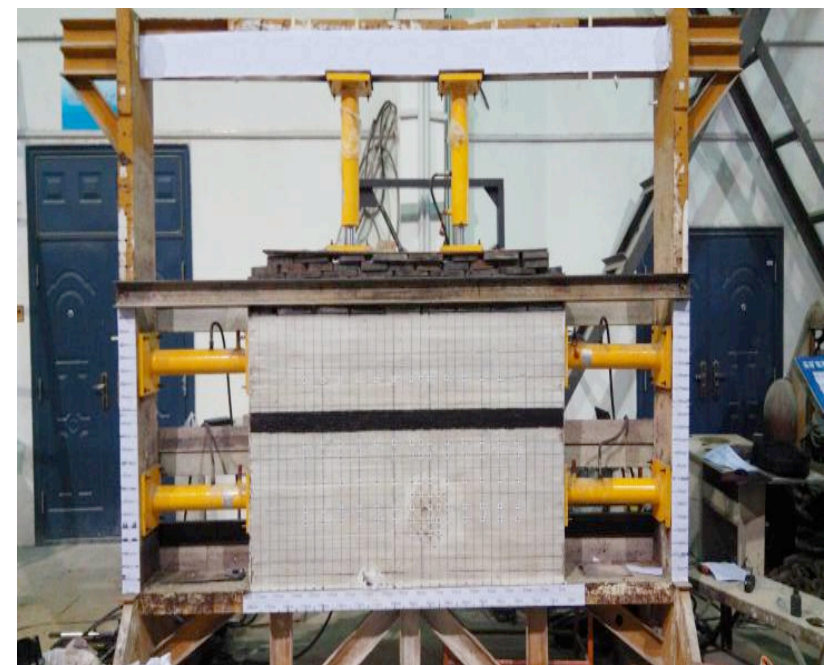

Fig. 4. Plane stress model experiment rig

\subsubsection{Matching similar materials and mechanical properties} of the test

The proportion of similar materials in this mechanical test was $8: 1: 0.8,10: 1: 1,12: 1: 1.2,14: 1: 1.4$, and 14:1:1.6, according to the ratio of aggregate (sand):cement materials (lime, cement):water. Among them, the proportion between sand and water was fixed at 10:1. Figure 5 shows the standard test specimens.

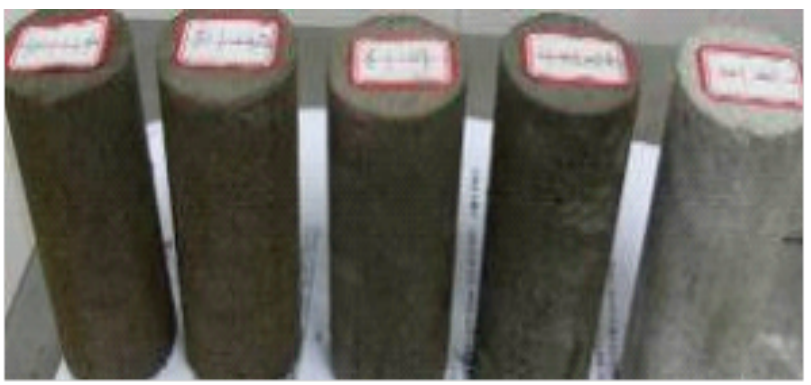

Fig. 5. Standard test specimens

Similar materials were placed inside standard cylindrical specimen vessels according to their particular proportion. The materials were divided into several subsections and compactly pressed until the specimen height reached above $100 \mathrm{~mm}$. The produced standard specimens were properly labeled and categorically placed in the laboratory. After approximately $21 \mathrm{~d}$, the specimens were grounded and processed, and their intensity parameters were tested in MTS mechanical testing machines, as shown in Table 2.

Table 2. Mechanical parameters of analog simulation material

\begin{tabular}{l|l|l|l|l|l}
\hline \multirow{2}{*}{$\begin{array}{l}\text { Mechanical parameters } \\
\text { of rock samples }\end{array}$} & \multicolumn{4}{|c}{ Similar material ratio, Aggregate :Cement: Water } \\
\cline { 2 - 5 } & $8: 1: 0.8$ & $10: 1: 1$ & $12: 1: 1.2$ & $14: 1: 1.4$ \\
\hline Elastic modulus/ GPa & 0.675 & 0.501 & 0.303 & 0.212 \\
Compressive strength/ MPa & 1.029 & 0.613 & 0.404 & 0.232 \\
Shear strength/ MPa & 0.398 & 0.248 & 0.164 & 0.130 \\
Tensile strength/ MPa & 0.205 & 0.126 & 0.108 & 0.127 \\
\hline
\end{tabular}

The three experiments revealed that with the decrease of the cement content, the compressive and shearing strengths of the specimens also decreased, whereas the proportion between aggregate and cement was always within a certain scope. On the basis of the strengths of the in situ rocks in the first section, the strengths of siltstone, mudstone, and raw coal were 18,12 , and $6 \mathrm{MPa}$, respectively. The strengths of the corresponding simulative materials were $0.33,0.22$, and $0.11 \mathrm{Mpa}$, considering a simulative stress ratio of 1:54.

Based on the results of the experiment in Table 1, bearing stress should be within $1 \mathrm{MPa}$. The proportion of materials of simulative siltstones, mudstones, and raw coals were 12:1:1.2; $14: 1: 1.4,16: 1: 1.6$ in order to satisfy the division of roadways bearing structure and to meet the need of observing the transformation and development of roadways. The respective compressive strengths were $0.404,0.232$, and $0.127 \mathrm{MPa}$, which all meet existing standards.

\subsubsection{Distribution of strain gauges around the roadway and the raster test}

Nine measuring points were distributed on each measuring line around the roadway. The distance between every two measuring points was $20 \mathrm{~mm}$. In the experiment, another seven measuring points were placed on each measuring line. The distance between every two measuring points was $40 \mathrm{~mm}$. Hence, a total of 16 measuring points were placed on each measuring line. The strain gauges were fixed along the radial and hoop directions using strain bricks. Figure 6 illustrates the theoretical principle.

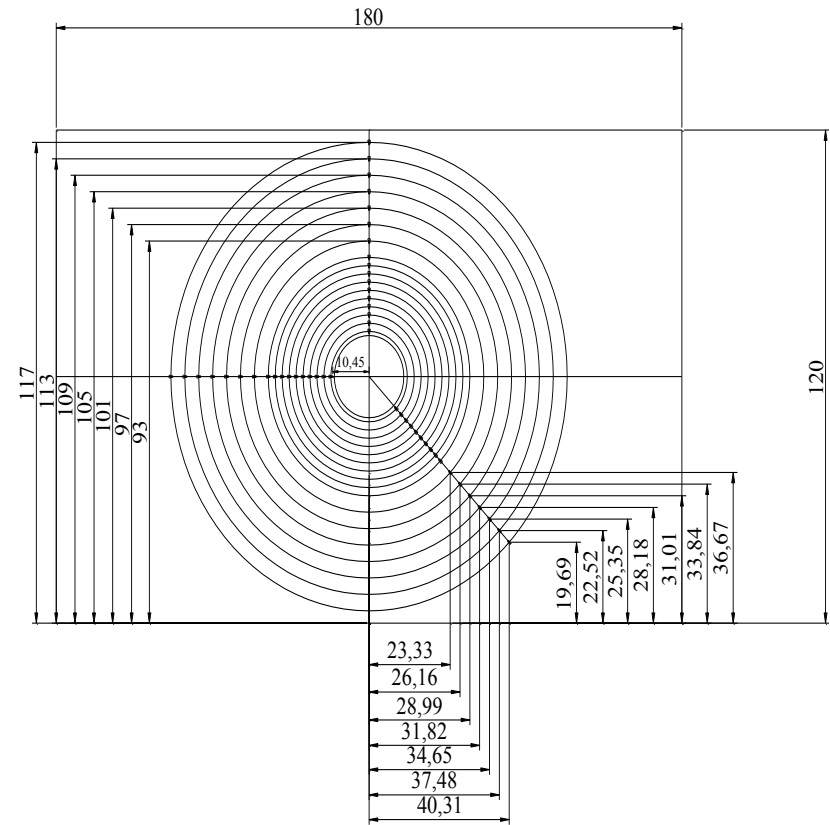

Fig. 6. Strain gauge setting around the roadway $(\mathrm{cm})$

To obtain the specific strains of the surrounding rocks around the roadway, which were influenced by the mining of the upper coal seam and tectonic stress, several raster testing lines were distributed on the experimental table. The distance between every two testing lines was $40 \mathrm{~cm}$. Figure 7 shows the distribution of actual objects. 

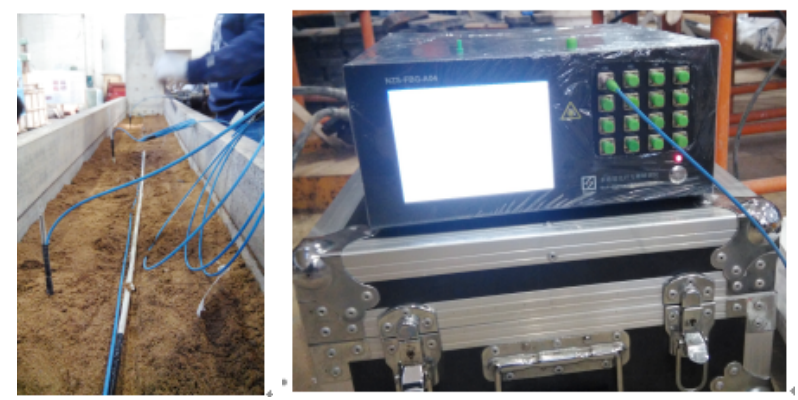

Fig. 7. Raster test device

\subsubsection{Design of coal mining and roadway excavation}

After the similar materials were placed in the experimental shelf, they were compactly pressed using a hydraulic jack for several days, which smoothened the model surfaces. The corresponding labels were placed around the roadway on the model surface by drawing pins to monitor the displacement of floor roadway surface, which was influenced by the mining work of the upper work face. Figure 8 demonstrates the process.

Once the basic upper work was finished, the roadway should be immediately extracted from the model to fit the instantaneous process of unloading of the excavation, as shown in Figure 9.

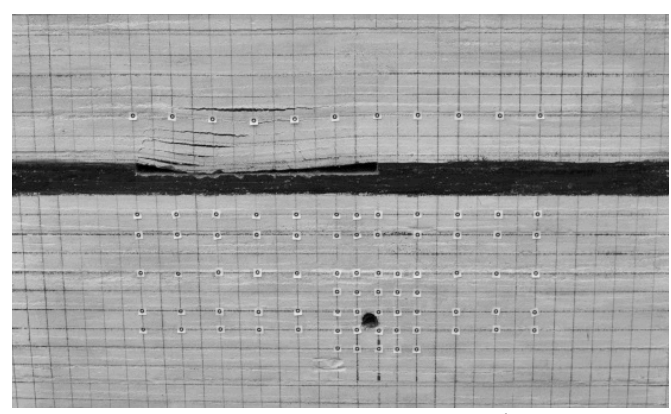

a 50 -m excavation

Fig. 10. Influence of upper face mining on floor roadway without horizontal pressure

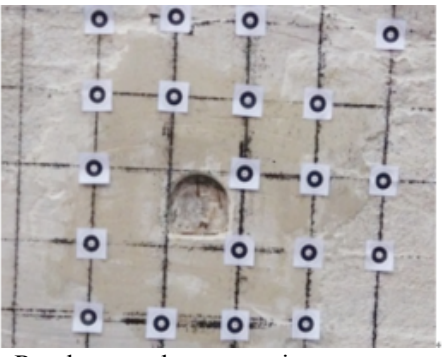

Fig. 8 Roadway under excavation

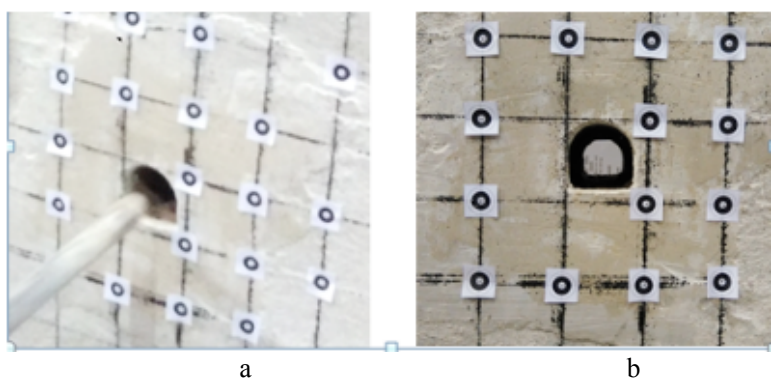

Fig. 9. Floor roadway of (a) during and (b) after excavation

To study the influence of stability on the naked roadway excavation caused by mining, the upper mining work face was mined step by step for $50 \mathrm{~m}$ and $80 \mathrm{~m}$ after the roadway excavation was finished, as shown in Figures 10 and 11.

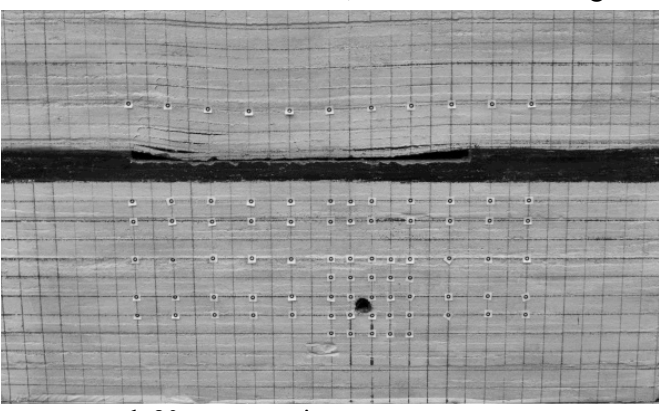

b 80-m excavation

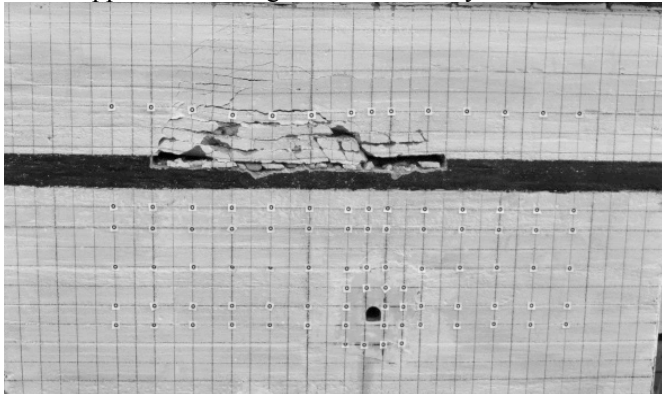

a 50-m excavation

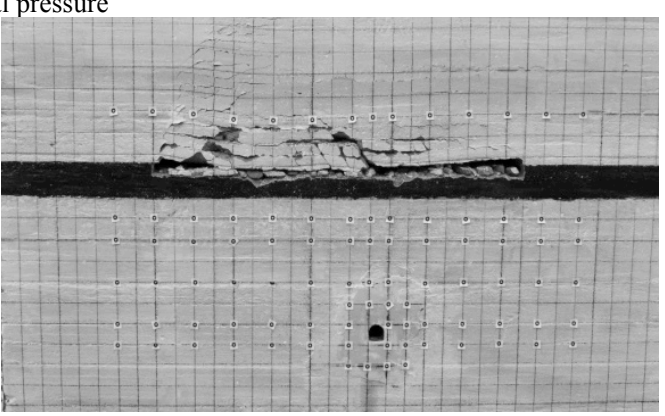

b 80-m excavation

Fig. 11. Influence of upper face mining on floor roadway under horizontal pressure

\subsubsection{Design of experimental plan}

The experiments were conducted in two groups. The first group of experiments was performed to simulate the influence of upper coal face mining on roadway stability without tectonic stress. The detailed experimental procedures are as follows. The depth of the model roadway was $625 \mathrm{~m}$, whereas the corresponding ground pressure $\mathrm{P}_{0}$ was $15.63 \mathrm{MPa}$. The roadway was exposed after being mined step by step. The strain values of all the testing lines in the surrounding rocks during the excavation process, which is the strain field, were measured. The secondary strain field was calculated in combination with Formula 3, and stability was analyzed. By contrast, the second group of experiments should simulate the influence of tectonic stress by changing its lateral pressure.
Given the stress loading similarity ratio of 1:54 and conversion relation between all lifting jack loads and boundary stresses in the experiment, the proportion of a single lifting jack and boundary loads in the vertical direction was 48.22:1, and its proportion in the horizontal direction was 32.14:1.

Table 3. Relationship between buried depth and stress loading

\begin{tabular}{c|c|c|c}
\hline \multicolumn{2}{c|}{ Stress ratio } & $\boldsymbol{\lambda}=\mathbf{1}$ & $\boldsymbol{\lambda}=\mathbf{1 . 5}$ \\
\hline \multirow{2}{*}{$\begin{array}{c}\text { Actual } \\
\text { stress/MPa }\end{array}$} & Vertical & 15.630 & 15.630 \\
\cline { 2 - 4 } & Level & 15.630 & 23.445 \\
\hline $\begin{array}{c}\text { Jack } \\
\text { loading/MPa }\end{array}$ & Vertical & 13.957 & 13.957 \\
\cline { 2 - 4 } & Level & 9.303 & 13.954 \\
\hline
\end{tabular}




\section{Results analysis and discussion}

To study the influence on the floor roadway stability caused by the mining on the upper mining face and the tectonic stress, the evolvement rule on the stress field of the surrounding rocks was calculated, and the roadway rupture development and the distribution law of the displacement field were observed.

\subsection{Roadway stress field without tectonic stress}

Without horizontal tectonic stress, the upper coal face was mined for $50 \mathrm{~m}$ and $80 \mathrm{~m}$ under a vertical pressure of 15.63 $\mathrm{MPa}$, the mining distance of the upper coal face is $50 \mathrm{~m}$ at the first step and $80 \mathrm{~m}$ at the second step. The secondary stress field distribution rules of the roadway without tectonic stress were calculated according to the strain field around the roadway of the grating test and the foil gauges and Formula 3. Figure 12 presents the details.
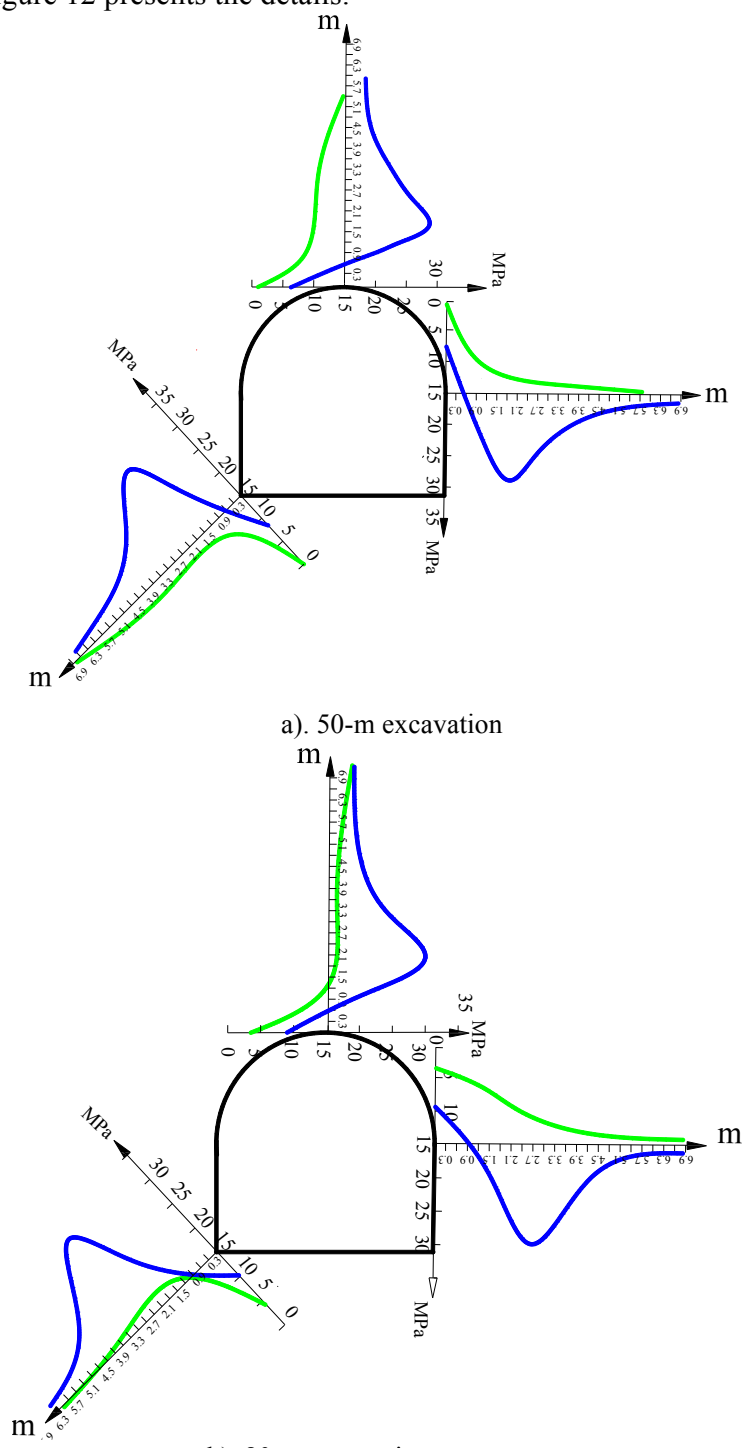

b). 80-m excavation

Fig.12. Roadway stress field distribution without tectonic stress

Without tectonic stress, Figure 12 indicates the following:

1) The mining distance of the upper coal face was $50 \mathrm{~m}$. First, after each measuring line was distributed, the load of the lifting jack in the horizontal and vertical directions was 9.304 $\mathrm{MPa}$ and $13.956 \mathrm{MPa}$, respectively. After the surrounding rocks became completely stable, data were gathered from the strain gauge of the bottom arch springing measuring line. The data indicated that the strain in the hoop direction in the first measuring point was $0.518 \times 10^{-3}$, and the strain in the radial direction was $0.063 \times 10^{-3}$. According to the elasticity modulus $\mathrm{E}=0.303 \mathrm{GPa}$ of the analog siltstone, the stresses obtained in the hoop and radial directions in the first measuring points were $0.157 \mathrm{MPa}$ and $0.019 \mathrm{Mpa}$, respectively. Then, on the basis of the stress similarity proportion, the data of actual stress obtained in the hoop and radial directions were $8.5 \mathrm{MPa}$ and 1.0 $\mathrm{MPa}$, respectively. The peak stress in the hoop direction in the measuring line was $30 \mathrm{MPa}$, and its distance from the roadway wall was $2.1 \mathrm{~m}$.

2) The mining distance of the upper coal face was $80 \mathrm{~m}$. Under the loading stresses of the horizontal and vertical lifting jacks with the other unchanged experimental conditions and advancing for another $30 \mathrm{~m}$ of the upper coal face, the actual stresses in the hoop and radial directions of the first measuring point were $11.5 \mathrm{MPa}$ and $4.1 \mathrm{MPa}$, respectively. The peak stress in the hoop direction of the measuring line was $32.5 \mathrm{MPa}$, and its distance from the roadway wall was $2.7 \mathrm{~m}$.

\subsection{Roadway Stress field under Tectonic stress}

The upper coal face was mined for $50 \mathrm{~m}$ and $80 \mathrm{~m}$ under a vertical pressure of $15.63 \mathrm{MPa}$ and horizontal tectonic stress of 23.445MPa. Formula 3 and Figure 13 present the distribution of the secondary stress field of the floor roadway under tectonic stress by using the strain gauge and raster.
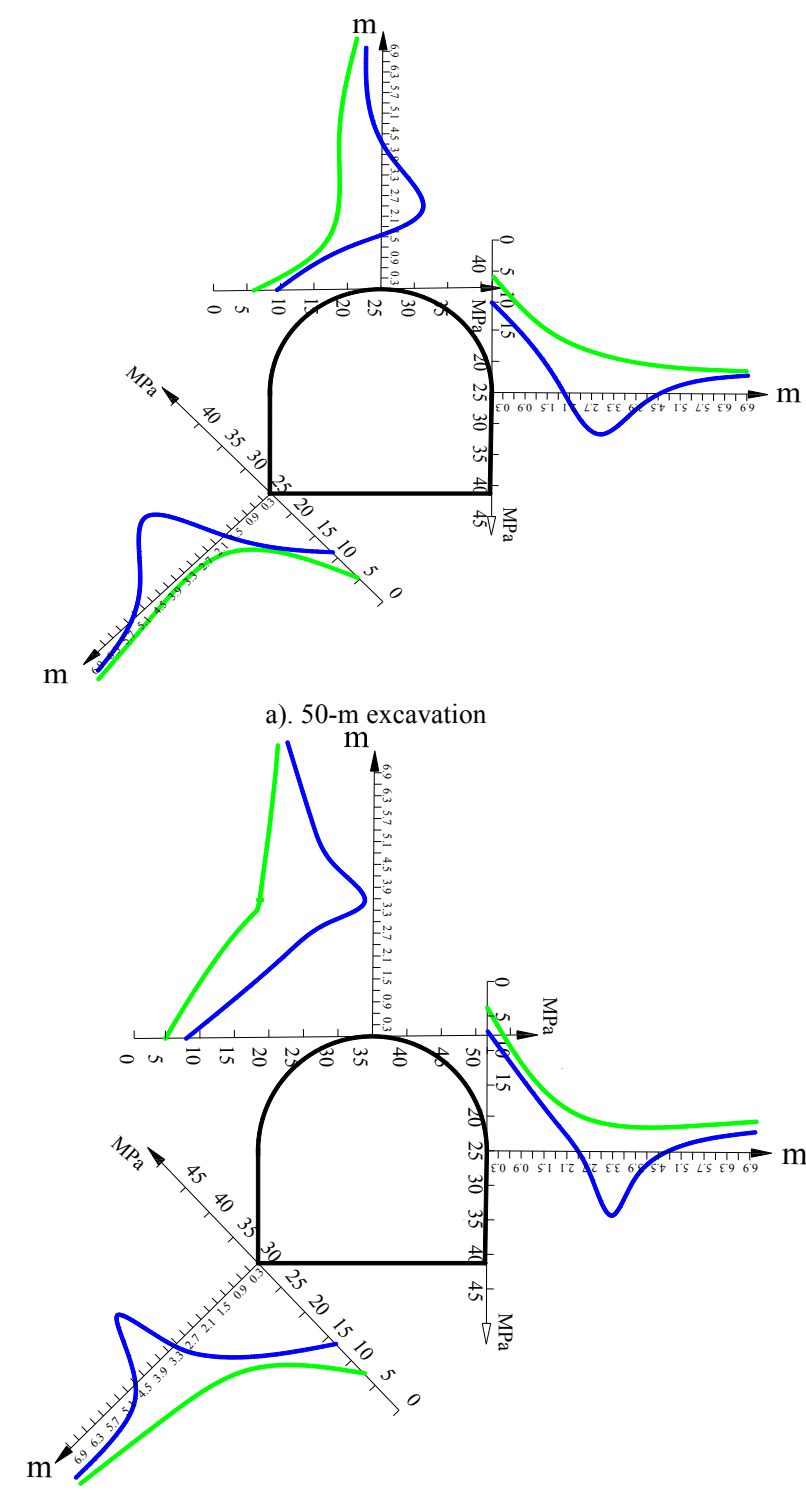

b). 80-m excavation

Fig. 13. Roadway stress field distribution under tectonic stress 
Figure 13 shows the distribution of the roadway stress field under tectonic stress. The details are as follows.

1) The mining distance of the upper coal face was $50 \mathrm{~m}$. First, after each measuring line was distributed, the load of the lifting jack in the horizontal and vertical directions was 9.304 $\mathrm{MPa}$ and $13.956 \mathrm{MPa}$, respectively. After the surrounding rocks became completely stable, data were gathered from the strain gauge of the bottom arch springing measuring line. The data indicated that the strain in the hoop direction in the first measuring point was $0.762 \times 10^{-3}$, and the strain in the radial direction was $0.342 \times 10^{-3}$. According to the elasticity modulus $\mathrm{E}=0.303 \mathrm{GPa}$ of the analog siltstone, the obtained stresses in the hoop and radial directions in the first measuring points were $0.231 \mathrm{MPa}$ and $0.104 \mathrm{Mpa}$, respectively. Then, on the basis of the stress similarity proportion, the data of the actual stress obtained in the hoop and radial directions were $12.5 \mathrm{MPa}$ and 5.6 $\mathrm{MPa}$, respectively. The peak stress in the hoop direction in the measuring line was $35.5 \mathrm{MPa}$, and its distance from the roadway wall was $3.0 \mathrm{~m}$.

2) The mining distance of the upper coal face was $80 \mathrm{~m}$. Under the loading stresses of the horizontal and vertical lifting jacks with the other unchanged experimental conditions and advancing another $30 \mathrm{~m}$ of the upper coal face, the actual stresses in the hoop and radial directions of the first measuring point were $14.5 \mathrm{MPa}$ and $7.5 \mathrm{MPa}$, respectively. The peak stress in the hoop direction of the measuring line was $38.5 \mathrm{MPa}$, and its distance from the roadway wall was $3.6 \mathrm{~m}$.

\subsection{Regulation of the deformation and instability of the surrounding rocks}

\subsubsection{Deformation of surrounding rocks}

On the basis of the model size $1.8 \mathrm{~m} \times 1.2 \mathrm{~m} \times 0.3 \mathrm{~m}$ and its geometric similarity proportion of $C_{L}=1: 45$, the strain data of the surrounding rocks around the roadway for $15 \mathrm{~d}$ was obtained through the strain gauge and raster. Figures 14 to 16 present the displacement change calculated by conversion.

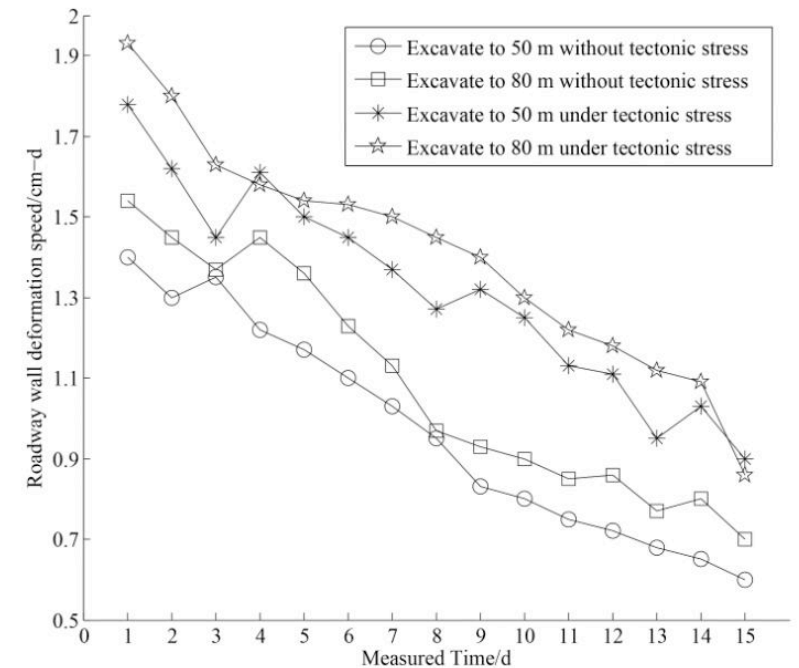

Fig.14. Influence of upper coal face mining on the roof deformation of floor roadway

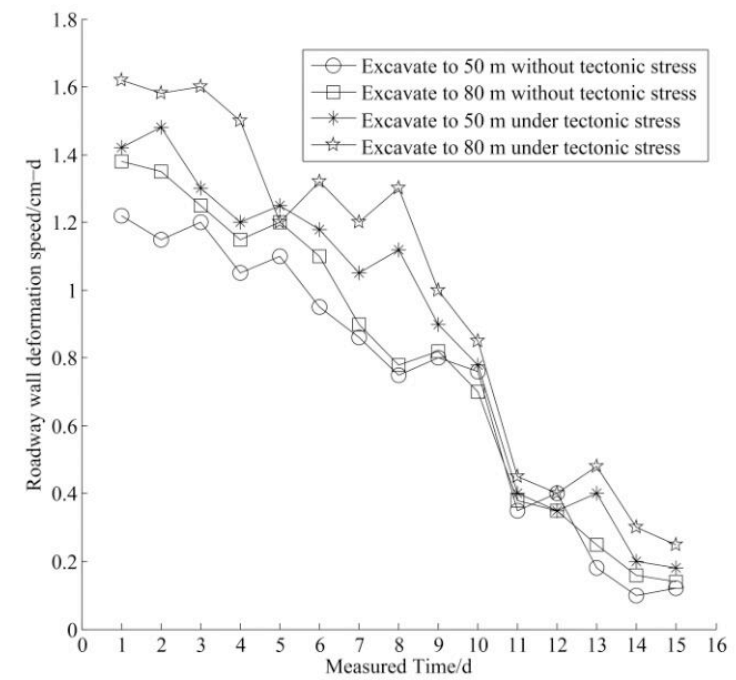

Fig.15. Influence of upper coal face mining on the side deformation of floor roadway

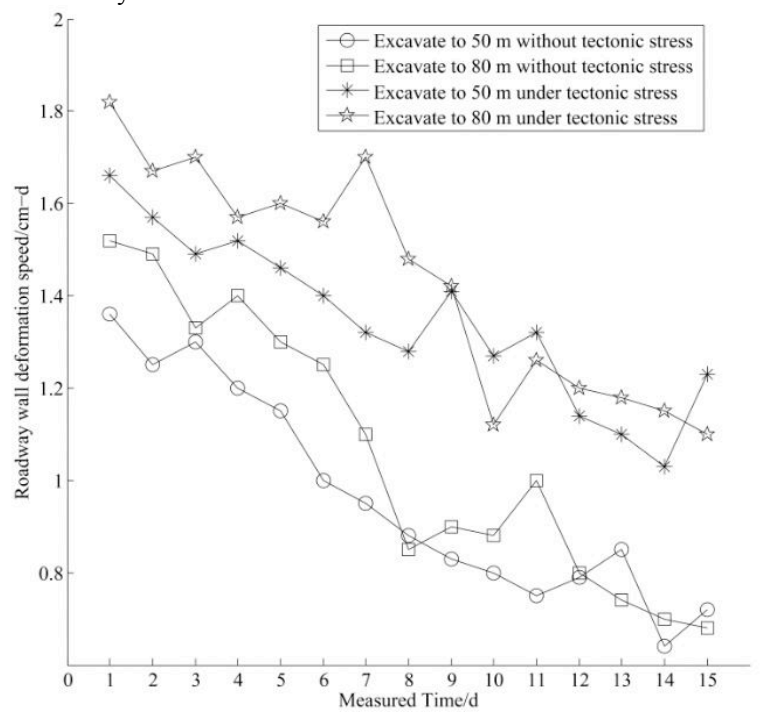

Fig.16. Influence of upper coal face mining on the floor deformation of roadway

As presented in Figures 14-16, after the upper coal face mining the deformation speed of the surrounding rocks of the floor roadway was dwindling and tended to stability gradually. Without tectonic stress, the speed of the roof deformation in the first $9 \mathrm{~d}$, the side deformation in the first $7 \mathrm{~d}$, and the floor deformation in the first $8 \mathrm{~d}$ exceeded $1.0 \mathrm{~cm} / \mathrm{d}$. Under tectonic stress, the speed of the roof deformation in the first $13 \mathrm{~d}$, the side deformation in the first $8 \mathrm{~d}$, and the floor deformation in the first $15 \mathrm{~d}$ exceeded $1.0 \mathrm{~cm} / \mathrm{d}$.

\subsubsection{Rules of roadway fracture development}

The rules of roadway fracture development were observed, and the influence of mining work in the upper coal face as well as the effect of tectonic stress on the fracture of the surrounding rocks of the floor roadway was studied. Then, the fracture development rules of the surrounding rocks in the floor roadway during the mining process were obtained, as shown in Figures 17 and 18. 


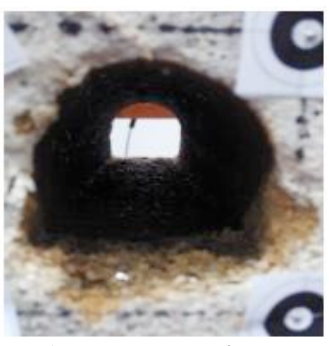

a). 50-m excavation

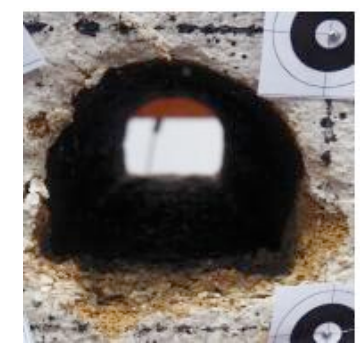

b). 80 -m excavation
Fig. 17. Roadway fracture rule without tectonic stress

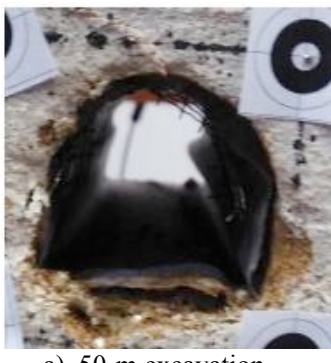

a). 50-m excavation

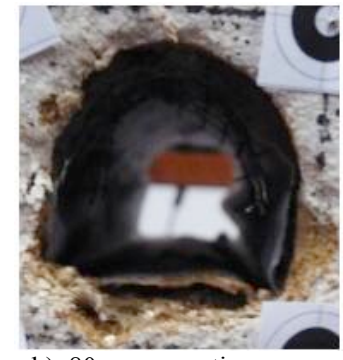

b). 80-m excavation
Fig. 18. Roadway fracture rule under tectonic stress

Figure 17 shows the fracture of the surrounding rocks, which sharply intensified with the mining of the work face. Figure 18 presents the extent and scope of the fracture around the roadway, which further intensified under tectonic stress.

\section{Conclusions}

To reveal the role of tectonic stress in the deformation and damage of floor roadway, a case study was conducted on the deformation characteristics of the surrounding rocks of mining floor roadways based on a similarity model test. Through the research on secondary stress distribution of the surrounding rocks, the following conclusions were drawn.

1) Under the same loading conditions, the secondary stress of the surrounding rocks transferred, the plastic flow increased, and the coefficient of stress concentration decreased along with the upper coal face mining. These results are unfavorable to the maintenance of roadway stability.

2) Under the same mining conditions, the stress concentration of the surrounding rocks under tectonic stress field was higher than that without tectonic stress. This phenomenon was more evident on the sides of roadway and at the end of the arch foot. However, the stress transferred more obviously and was prone to shear failure.

Thus, the upper coal face mining and the influence of crustal stress were considered in the similar physical simulation. Through comparison, the study analyzed the rule change of the roadway stress, displacement, and rupture fields under the influence of stress, which revealed the control mechanism of the multiple upper mining on the stability of the floor roadway. Thus, scientific basis for the advanced control and management of roadway deformation under tectonic stress was provided.

Given the practical situation of the layout of underground roadways, the directions of roadway layout and tectonic stress often appear in multiple angles, which can be the focus in future research. Considering these angles simultaneously under the similar physical simulation is difficult; thus, a corresponding numerical simulation is needed. Selecting a specific angle for a similar simulation should be considered in future studies.

\section{Acknowledgement}

The study was supported by the Natural Science Foundation of China(Grant No. 41272278).

This is an Open Access article distributed under the terms of the Creative Commons Attribution Licence

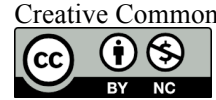

\section{References}

1. Martin C. D., Kaiser P. K., Christiansson R., "Stress, instability and design of underground excavations". International Journal of Rock Mechanics \& Mining Sciences, 40(7-8), 2003, pp.1027-1047.

2. He, M., Jia, X., Gong, W., Faramarzi, L., "Physical modeling of an underground roadway excavation in vertically stratified rock using infrared thermography." International Journal of Rock Mechanics \& Mining Sciences, 47(7), 2010, pp.1212-1221.

3. Zhai, X. R., Wu, J. W., Shen, S. H., Han, Y., "Study on similar material simulation of rock mass mining stress at fault boundary". Journal of Safety Science and Technology, (5), 2014, pp.56-61.

4. Kulatilake, P. H. S. W., Wu, Q., Yu, Z., Jiang, F., "Investigation of stability of a tunnel in a deep coal mine in China". International Journal of Mining Science and Technology, 23(4), 2013, pp.579. 589.

5. Feng, X. T., Zhang C., Qiu S., "Dynamic design method for deep hard rock tunnels and its application". Journal of Rock Mechanics and Geotechnical Engineering, 8(4), 2014, pp.443-461.

6. Griffith W. A, Becker J, Cione K., "3D topographic stress perturbations and implications for ground control in underground coal mines". International Journal of Rock Mechanics \& Mining Sciences, 70(9), 2014, pp.59-68.

7. Kang, H. P., "Ananlysis on types and interaction of stress fields in underground coal mines”. Journal of China Coal Society, 33(12), 2008, pp.1329-1335.

8. Anastasopoulos I., Gazetas G., "Analysis of cut-and-cover tunnels against large tectonic deformation". Bulletin of Earthquake Engineering, 8(2), 2010, pp.283-307.

9. Zhu, Z., Li, Y., Xie, J., "The effect of principal stress orientation on tunnel stability". Tunnelling and Underground Space Technology, 49, 2015, pp.279-286.
10. Li, T., Mu, Z., Liu, G., "Stress spatial evolution law and rockburst danger induced by coal mining in fault zone". International Journal of Mining Science \& Technology, 26(3), 2016, pp.409-415.

11. Chang, Y., "Similarity simulation of bolt support in a coal roadway in a tectonic stress field". International Journal of Mining Science and Technology, 20(5), 2010, pp.718-722.

12. Müller R. D., Yatheesh V., Shuhail M., "The tectonic stress field evolution of India since the Oligocene". Gondwana Research, 28(2), 2015, pp.612-624.

13. Yang, S., Huang, L., Xie, F., "Quantitative analysis of the shallow crustal tectonic stress field in China mainland based on in situ stress data". Journal of Asian Earth Sciences, 85(2), 2014, pp.154-162.

14. Vallejo L. I. G. D., Hijazo T., "A new method of estimating the ratio between in situ rock stresses and tectonics based on empirical and probabilistic analyses". Engineering Geology, 101(3), 2008, pp.185-194.

15. Scussel D., Chandra S., "A new approach to obtain tunnel support pressure for polyaxial state of stress". Tunnelling and Underground Space Technology, 36(2), 2013, pp.80-88.

16. Exadaktylos G. E., Stavropoulou M. C., "A closed-form elastic solution for stresses and displacements around tunnels". International Journal of Rock Mechanics and Mining Sciences, 39(7), 2002, pp.905-916.

17. Zhao, W., Han, L., Zhang, Y., "Study on the influence of principal stress on the stability of surrounding rock in deep soft rock roadway". Journal of Mining and Safety Engineering, 32(3), 2015, pp.504-510.

18. Wang, Y., "Analysis, control and forecast of deformation and pressure in soft rock tunnel". Chinese Journal of Rock Mechanics and Engineering, 23(1), 2004, pp.158-158. 
19. Shen, J., Zhu, H., Luo, M., Liu, D., "Numerical simulation of co distribution discharged by flame-proof vehicle in underground tunnel of coal mine". Journal of Loss Prevention in the Process Industries, 40(4739), 2015, pp.117-121.

20. Eberhardt, E., "Numerical modelling of three-dimension stress rotation ahead of an advancing tunnel face". International Journal of Rock Mechanics and Mining Sciences, 38(4), 2001, pp.499-518.

21. Baziar, M. H., Nabizadeh, A., Mehrabi, R., Lee, C. J., Wen, Y. H., "Evaluation of underground tunnel response to reverse fault rupture using numerical approach". Soil Dynamics and Earthquake Engineering, 83(130), 2016, pp.1-17.

22. He, M. C., "Physical modeling of an underground roadway excavation in geologically $45^{\circ}$ inclined rock using infrared thermography $\lesssim$.

23. He, F., Zhang, G., "Stability analysis and control of deep underground roadways subjected to high horizontal tectonic stress". Journal of China University of Mining and Technology, 44(3), 2015, pp.466-476.
24. Guo, Z., Li, E., Zhang, Y., Deng, X., Wang, J., "Study on deformation and failure mechanism of the tectonic stress areas' soft rock roadway in nanshan coal mine". Journal of Mining and Safety Engineering, 32(2), 2015, pp.267-272.

25. Zheng, S. B., "3D geostress field distribution and roadway layout optimization in Sihe Mine". Journal of China Coal Society, 35(5), 2010, pp.717-722.

26. Xiao, T. Q., Li, H. Z., Zhi, G. H., "Experimental study on similar simulation for surrounding rock stability of deep roadway with thick top coal". Journal of China Coal Society, 39(6), 2014, pp.1016-1022(7).

27. Li, Zh. H., Guan, F. H., Pan, Y. S., "Analysis of stress field of rock surrounding circular roadway based on damage theory". Rock and Soil Mechanics, 25(S2), 2004, pp.160-163.

28. Jiang, B. S, Yang, L., Shi, L., P., "Stress analysis of cracked surrounding rock based on hoek-brown criterion". Chinese Journal of Solid Mechanics. (S1), 2011, pp.300-305. 